\section{Healthcare sector efficiency in Gujarat (India): an exploratory study using data envelopment analysis}

\author{
Brijesh C. Purohit \\ Madras School of Economics, Kottur, \\ India
}

\section{Abstract}

The importance of efficiency in resource utilization in healthcare sector has been recognized globally. In this paper we focus on efficiency of healthcare system at sub-state level (i.e., district level) in India using Gujarat state and its district level data for 2012-13. In spite of being an economically advanced state, in terms of infant mortality rate (IMR) the state is not the lowest. We explore the reasons for relative performance of different districts with data envelopment analysis (DEA). We used IMR as output variables. Using principal component analysis we tried a sub-set of variables, which had low correlations. Thus, four factor scores relating to medical officer, lady medical officer, Ayurveda, Yoga and Naturopathy, Unani, Siddha and Homoeopathy doctor, pharmacist, were used for DEA. We have focused on Charnes, Cooper, and Rhodes scores (or constant returns to scale technical efficiency score), and discussed efficiency rankings based on these. Thus, our results pertaining to district level health system efficiency in Gujarat State indicate that some of the districts have low efficiency in utilization of inputs like doctors, beds and workload per health institutions. There are also other districts, which need more of these inputs, which may enhance their output and efficiency. Thus, it is suggested that the efficiency in Valsad needs an improvement much more than other districts, whereas districts like Ahmadabad and Surat need more of both medical manpower and facilities. Even in case of Vadodara and Rajkot, the ranking in terms of most of medical manpower and facilities is low and thus these districts may also be benefitted by additional inputs. Hence, there is a mix of both inefficiency and inadequacy of inputs, which is reflected in our results.

\section{Introduction}

The importance of efficiency in resource utilization in healthcare sector has been emphasized by a number of empirical stud- ies. ${ }^{1,2}$ Both a unit level and the aggregate level analyses have been attempted. Some researchers have focused on hospitals, nursing homes, health maintenance organizations (HMOs) and district health authorities. ${ }^{3-9}$ Generally either of the methods, namely, nonparametric or parametric is employed. Among the former, data envelopment analysis (DEA) is popular. Among the latter, an idealized yardstick is developed that is used to evaluate economic performance of health system. These methods provide a production possibility frontier depicting a locus of potentially technical efficient output combination that an organization or health system is capable of producing at a point in time. An output combination below this frontier is termed as technically inefficient. ${ }^{10-12}$ There exists an exhaustive array of reviews which provides us in detail the steps followed and empirical problems that have been faced by the researchers. ${ }^{13,3}$ Nonetheless, there are a very few studies in the developing countries' context. In the Indian context, the focus has mostly remained either on the allIndia rural or urban sector or the analysis has been carried out up to the state level aggregates only. So far, a district level analysis has been attempted for a few states including Punjab, Maharashtra, Karnataka, West Bengal and Madhya Pradesh. ${ }^{14}$ We extend our analysis in this paper to focus on efficiency of the healthcare system at sub-state level (i.e., district level) in India using Gujarat state and its district level data. We explore the reasons for relative performance of different districts with DEA. Gujarat is one of the high-income Indian states and with its above national average income at INR per capita 59,157 at constant prices, is third next to Maharashtra and Harayana (Table 1). Situated in the western part of India with capital city as Gandhinagar, the state covers an area of $196,204 \mathrm{~km}^{2}(75,755 \mathrm{sq}$ miles$)$ and a population above 60 million. The state is bordered by the states of Rajasthan, Maharashtra, and Madhya Pradesh. In terms of literacy (2011 census), growth in literacy (between 20012011) and per capita health expenditure the state occupies a rank of 5, 6 and 7 respectively among the major Indian states (Table 1).

In terms of infant mortality rate (IMR) (total): rural and urban, in 2013 , it is $8^{\text {th }}, 11^{\text {th }}$ and $4^{\text {th }}$ rank (Table 2 ). The IMR in various districts of Gujarat varies considerably. The relative position of different districts in terms of IMR, often considered as an important indicator of health status leaving aside the case of exception of Sabar Kantha district, varies from 2 (in Banas Kantha, Dohad, Panch Mahals and Porbandar) to 14 (in Ahmadabadand Surat). ${ }^{16}$

In this paper, we make an attempt to find out technical efficiency using a non-parametric approach known as DEA. ${ }^{11,12}$
Correspondence: Brijesh C. Purohit, Madras School of Economics, Gandhi Mandapam Road, Kottur, Chennai 600025, India.

Tel. +91.044.2230.0304 - Fax: +91.044.2235.4847.

E-mail: brijeshpurohit@gmail.com

Key words: Efficiency; Healthcare system; District level; IMR

Received for publication: 20 September 2015

Revision received: 4 March 2016.

Accepted for publication: 7 March 2016.

This work is licensed under a Creative Commons Attribution 4.0 License (by-nc 4.0).

(C) Copyright B.C. Purohit, 2016

Licensee PAGEPress, Italy

Healthcare in Low-resource Settings 2016; 4:5525 doi:10.4081/hls.2016.5525

\section{Materials and Methods}

The DEA methodology, originating from Farrell's (1957) and further by Charnes, Cooper and Rhodes (1978), assumes the existence of a convex production frontier. The production frontier in the DEA approach is constructed using linear programming methods. The term envelopment stems from the fact that the production frontier envelops the set of observations. ${ }^{11,12}$

The general relationship that we consider is given by the following function for each district $i$ :

$$
Y_{i}=f\left(X_{i}\right), i=1 \ldots \ldots \ldots(1)
$$

where we have $Y i$ - our output measure; $X i$ the relevant inputs. If $Y_{i}<f\left(X_{i}\right)$, it is said that unit $i$ exhibits inefficiency. For the observed input levels, the actual output is smaller than the best attainable one and inefficiency can then be measured by computing the distance to the theoretical efficiency frontier.

The variable-returns to scale hypothesis, which we use here for an output-oriented specification, is described as below. Suppose there are $k$ inputs and $m$ outputs for $n$ decision management units (DMUs). For the i-th DMU, we can define $X$ as the $(k \times n)$ input matrix and $Y$ as the $(m \times n)$ output matrix. The DEA model is then specified with the following mathematical programming problem, for a given i-th DMU:

$$
\begin{gathered}
\operatorname{Max}_{\delta, \lambda} \delta \\
\text { Subject to }-\delta \mathrm{yi}+\mathrm{Y} \lambda \geq 0 \\
\mathrm{xi}-\mathrm{X} \lambda \geq 0 \ldots \ldots(2) \\
\mathrm{nl}{ }^{\prime} \lambda{ }^{\prime}=1 \\
\lambda \geq 0
\end{gathered}
$$


In problem (2), $\delta$ is a scalar (that satisfies $1 / \delta \leq 1)$, more specifically it is the efficiency score that measures technical efficiency. It measures the distance between a unit and the efficiency frontier, defined as a linear combination of the best practice observations. With $1 / \delta<1$, the unit is inside the frontier (i.e., it is inefficient), while $\delta=1$ implies that the unit is on the frontier (i.e., it is efficient).

The vector $\lambda$ is a $(n \times 1)$ vector of constants that measures the weights used to compute the location of an inefficient DMU if it were to become efficient, and $n 1$ is an n-dimensional vector of ones. The inefficient DMU would be projected on the production frontier as a linear combination of those weights, related to the peers of the inefficient DMU. The peers are other DMUs that are more efficient and are therefore used as references for the inefficient DMU. The restriction $n 1^{\prime} \lambda=1$ imposes convexity of the frontier, accounting for variable returns to scale. Dropping this restriction would amount to admit that returns to scale were constant. Problem (2) has to be solved for each of the $n$ DMUs in order to obtain the $n$ efficiency scores.

Figure 1 presents the DEA production possibility frontier in the simple one input-one output case. States A, B and C are efficient. Their output scores are equal to 1 . State D is not efficient. Its score $[d 2 /(d 1+d 2)]$ is smaller than 1 .

There are some advantages in using DEA relative to a parametric method. This frame- work of estimation has the ability, for instance: i) to incorporate inputs and outputs that have different units; ii) to capture multiple input outputs; iii) to not necessitate specification of functional form relating inputs and outputs; and iv) to make a direct comparison between a DMU and other peers easily possible. Despite the advantages DEA imbibes some limitations in it. These include: i) it is a relative efficiency measure of a DMU and does not provide a theoretical maximum; ii) it is a non-parametric approach in DEA and thus a statistical hypoth- esis test may be difficult; and iii) it involves large computational problems as it creates for each DMU a linear program separately.

\section{Results and Discussion}

We used the IMR as an output variable. This measure is chosen as an indicator of output at district level for three reasons. First, it is presumed that given a normal circumstance (of

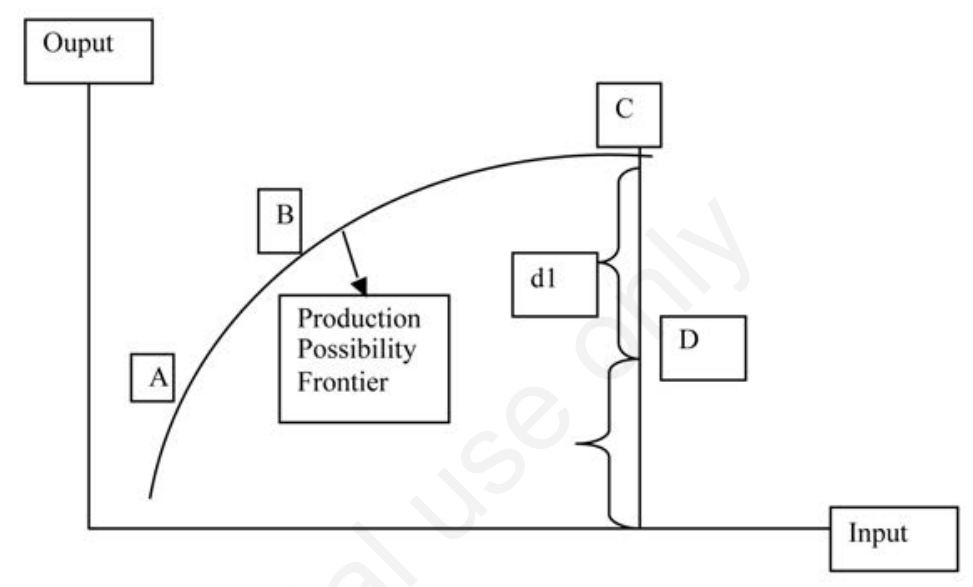

Figure 1. Data envelopment analysis production possibility frontier in one input-one output case.

Table 1. Rank of Gujarat among major Indian states in terms of per capita income, literacy and public expenditure on health.

\begin{tabular}{|c|c|c|c|c|c|c|c|c|}
\hline State & $\begin{array}{c}\text { NSDP } \\
\text { per capita } \\
\text { in 2012-13 (INR) }\end{array}$ & Rank* & $\begin{array}{c}\text { Literacy rate (\%) } \\
2011 \text { census }\end{array}$ & Rank* & $\begin{array}{c}\text { Decadal } \\
\text { difference (\%) }\end{array}$ & Rank* & $\begin{array}{l}\text { Per capita total public } \\
\text { expenditure on } \\
\text { health } 2009 \text {-10 (INR) }\end{array}$ & Rank* \\
\hline Andhra Pradesh & 39,645 & 9 & 67.41 & 17 & 7.19 & 12 & 459 & 9 \\
\hline Assam & 22,273 & 17 & 73.18 & 11 & 9.93 & 7 & 715 & 2 \\
\hline Bihar & 14,356 & 19 & 63.82 & 19 & 16.82 & 1 & 210 & 19 \\
\hline Chhattisgarh & 28,087 & 13 & 71.04 & 12 & 6.38 & 17 & 380 & 15 \\
\hline Gujarat & 59,157 & 3 & 79.31 & 5 & 10.17 & 6 & 480 & 7 \\
\hline Haryana & 64,052 & 2 & 76.64 & 8 & 8.73 & 9 & 483 & 6 \\
\hline Jammu and Kashmir & 30,035 & 12 & 68.74 & 15 & 13.22 & 4 & 1073 & 1 \\
\hline Jharkhand & 27,010 & 14 & 67.63 & 16 & 14.07 & 2 & 264 & 18 \\
\hline Karnataka & 43,266 & 8 & 75.6 & 9 & 8.96 & 8 & 468 & 8 \\
\hline Kerala & 55,643 & 5 & 93.91 & 1 & 3.14 & 19 & 580 & 4 \\
\hline Madhya Pradesh & 24,867 & 16 & 70.63 & 13 & 6.89 & 14 & 312 & 17 \\
\hline Maharashtra & 65,095 & 1 & 82.91 & 2 & 6.03 & 18 & 420 & 11 \\
\hline Odisha & 25,163 & 15 & 73.45 & 10 & 10.37 & 5 & 405 & 13 \\
\hline Punjab & 47,854 & 7 & 76.68 & 7 & 7.03 & 13 & 401 & 14 \\
\hline Rajasthan & 30,839 & 11 & 67.06 & 18 & 6.65 & 16 & 457 & 10 \\
\hline Tamil Nadu & 58,360 & 4 & 80.33 & 3 & 6.88 & 15 & 579 & 5 \\
\hline Uttar Pradesh & 18,635 & 18 & 69.72 & 14 & 13.45 & 3 & 372 & 16 \\
\hline Uttarakhand & 55,375 & 6 & 79.63 & 4 & 8.01 & 11 & 625 & 3 \\
\hline West Bengal & 34,177 & 10 & 77.08 & 6 & 8.44 & 10 & 410 & 12 \\
\hline All India & 38,856 & - & 74.04 & - & 64.83 & - & - & - \\
\hline
\end{tabular}

NSDP, net state domestic product; INR, Indian rupee. Part of data is taken from Purohit, Government of India and of Gujarat. ${ }^{14-17}$ *The highest in value is denoted as 1. 
no calamities, etc.), the allocation of Government budget at district level within the state might get reflected in better budgetary allocation at district level. Second, since district level budgetary estimates for life expectancy or budgetary allocation are not available, we presume that IMR is related to survival rate [since infant survival rate $=(1000-$ IMR $) /($ IMR $)]$, and thus it is a representative output variable for the health sector and it captures the impact of economic development as well. Third, it is necessary to keep in view the trend in health efficiency literature, which has focused on either life expectancy or IMR as output at country, state, or district levels.
Using a principal component analysis we tried a sub-set of variables, which had low correlations. The choice of input variables is guided by the basic classification of input variables used in healthcare provision, viz., manpower, capital investment (equipments, buildings, etc.) and materials. Among these, the manpower in the health sector is represented by the availability of medical and paramedical personnel. These included medical officer, lady medical officer, Ayurveda, Yoga and Naturopathy, Unani, Siddha and Homoeopathy doctor (i.e., a doctor who practices either of Ayurvedic or Unani or Siddha system of treatment; the acronym AYUSH is used by the Indian Ministry of Health), and pharmacist.
The second major input category in the health sector, namely, capital investment is represented by tribal beds, community health centers (CHCs), sub-divisional hospital. Since the utilization of these facilities is possible only if both the adequate manpower and material resources exist, we considered some of the utilization variables like ante-natal care (ANC) registered, percentage of ANC 3 checkup against ANC registered, delivery in governmental institutions and home delivery. The correlation matrix for these variables is presented below in Table 3. Based on these results, we calculated the principal components or factors and criteria of eigen value greater than one to select the factors for DEA

Table 2. Rank of Gujarat among major Indian states in terms of infant mortality rate in 2013.

\begin{tabular}{|c|c|c|c|c|c|c|}
\hline \multirow{2}{*}{ India/states/union territories } & \multicolumn{4}{|c|}{ IMR } & \multirow[b]{2}{*}{ Urban } & \multirow[b]{2}{*}{ Rank* $^{*}$} \\
\hline & Total & Rank* & Rural & Rank* & & \\
\hline Andhra Pradesh & 39 & 11 & 44 & 12 & 29 & 11 \\
\hline Assam & 54 & 18 & 56 & 18 & 32 & 13 \\
\hline Bihar & 42 & 13 & 42 & 10 & 33 & 15 \\
\hline Chhattisgarh & 46 & 14 & 47 & 14 & 38 & 17 \\
\hline Gujarat & 36 & 8 & 43 & 11 & 22 & 4 \\
\hline Haryana & 41 & 12 & 44 & 12 & 32 & 13 \\
\hline Jammu and Kashmir & 37 & 9 & 39 & 9 & 28 & 10 \\
\hline Jharkhand & 37 & 9 & 38 & 8 & 27 & 9 \\
\hline Karnataka & 31 & 5 & 34 & 6 & 24 & 7 \\
\hline Kerala & 12 & 1 & 13 & 1 & 9 & 1 \\
\hline Madhya Pradesh & 54 & 18 & 57 & 19 & 37 & 16 \\
\hline Maharashtra & 24 & 3 & 29 & 4 & 16 & 2 \\
\hline Odisha & 51 & 17 & 53 & 16 & 38 & 17 \\
\hline Punjab & 26 & 4 & 28 & 3 & 23 & 6 \\
\hline Rajasthan & 47 & 15 & 51 & 15 & 30 & 12 \\
\hline Tamil Nadu & 21 & 2 & 24 & 2 & 17 & 3 \\
\hline Uttar Pradesh & 50 & 16 & 53 & 16 & 38 & 17 \\
\hline Uttarakhand & 32 & 7 & 34 & 6 & 22 & 4 \\
\hline West Bengal & 31 & 5 & 32 & 5 & 26 & 8 \\
\hline India & 40 & - & 44 & - & 27 & - \\
\hline
\end{tabular}

IMR, infant mortality rate. Part of data is taken from Government of India. ${ }^{15}$ *The lowest IMR (in value) is denoted as 1 (or top rank).

Table 3. Correlation matrix.

\begin{tabular}{|c|c|c|c|c|c|c|c|c|c|}
\hline Medical officer & 1 & & & & & & & & \\
\hline Lady medical officer & -0.0257 & 1 & & & & & & & \\
\hline AYUSH doctor & 0.1193 & -0.3024 & 1 & & & & & & \\
\hline Pharmacist & 0.5279 & 0.0598 & 0.4052 & 1 & & & & & \\
\hline Tribal beds & -0.2397 & 0.1277 & 0.3335 & 0.2082 & 1 & & & & \\
\hline $\mathrm{CHCs}$ & 0.289 & 0.1835 & 0.587 & 0.5706 & 0.4887 & 1 & & & \\
\hline Sub divisional hospital & -0.1687 & 0.5017 & 0.1073 & 0.0341 & 0.2194 & 0.4798 & 1 & & \\
\hline ANC registered & -0.5342 & 0.3497 & -0.2834 & -0.2655 & 0.3601 & -0.1061 & 0.2098 & 1 & \\
\hline Percentage of ANC 3 checkup against ANC registered & 0.4534 & 0.0371 & 0.1399 & 0.1918 & 0.0523 & 0.0135 & -0.1177 & -0.4523 & \\
\hline Delivery in governmental institutions & -0.4324 & 0.0859 & -0.2213 & -0.2052 & 0.2885 & -0.2108 & -0.0731 & $0.4571 \quad-0.3059$ & 1 \\
\hline Home delivery & -0.353 & -0.0032 & -0.1119 & -0.5539 & -0.1952 & -0.2773 & 0.0428 & $0.4308-0.3997$ & 0.2289 \\
\hline
\end{tabular}

AYUSH, Ayurveda, Yoga and Naturopathy, Unani, Siddha and Homoeopathy; CHCs, community health centers; ANC, ante-natal care. 
and these are presented in Table 4. Four factor scores relating to medical officer, lady medical officer, AYUSH doctor, pharmacist were used for DEA.

The results of DEA are presented in Table 5. These results pertain to the variable returns to scale (VRS). However, the constant returns-toscale (the Charnes, Cooper, and Rhodes score, i.e. (CR) is a kind of global efficiency measurement that can be decomposed as: CCR score $=$ (pure) efficiency score $\mathrm{x}$ scale efficien$c y=V R S$ score $x$ scale efficiency. The results in this sheet show CCR scores and the scale efficiencies as defined above. Note that if a unit is fully efficient under the constant returns-toscale assumption, it is also fully efficient under the VRS one, but the converse is not necessarily true.

The returns-to-scale column contains the characterization of the area where each unit operates, that is, whether scale inefficiencies are due to an increasing or a decreasing returns-to-scale. In Table 5 we have focused on the CCR scores, and efficiency rankings based on these are discussed.

As presented in Table 5, except for Banas Kantha and Porbandar, all districts fall below the CCR score of one. Hence, the districts are compared to their peers using rank one as the highest efficiency and numerical higher values of ranks relatively indicate a more inefficient district. To explore further this efficiency aspect, we considered an all-district (24 districts) group average (or mean) and compared with the individual district's CCR. We also present the group averages for the CCR scores in the last row (column 5) of Table 5. By using deviations from these group averages, it can be observed that there is a substantial scope for an improvement in efficiency of low ranking districts. There are 14 districts that have the CCR scores lower than the group average of 0.4105 . The lowest among these remains Surat followed by Valsad. So, among all the districts there seems to be the highest need for these districts to enhance their efficiency even to catch up with the all-district average. There are another 10 districts, which are above the group average. Dohad district, followed by

Table 4. Principal components.

\begin{tabular}{lcccc} 
Component & Eigen value & Difference & Proportion & Cumulative \\
Comp1 & 3.3372 & 0.9565 & 0.3034 & 0.3034 \\
Comp2 & 2.3807 & 0.9713 & 0.2164 & 0.5198 \\
\hline Comp3 & 1.4094 & 0.2657 & 0.1281 & 0.6479 \\
Comp4 & 1.1437 & 0.3245 & 0.1040 & 0.7519 \\
\hline Comp5 & 0.8192 & 0.2054 & 0.0745 & 0.8264 \\
Comp6 & 0.6138 & 0.1391 & 0.0558 & 0.8822 \\
\hline Comp7 & 0.4746 & 0.1482 & 0.0431 & 0.9253 \\
Comp8 & 0.3264 & 0.0763 & 0.0297 & 0.9550 \\
\hline Comp9 & 0.2501 & 0.1042 & 0.0227 & 0.9777 \\
Comp10 & 0.1459 & 0.0468 & 0.0133 & 0.9910 \\
\hline Comp11 & 0.0991 & - & 0.0090 & 1.0000 \\
\hline
\end{tabular}

Table 5. Data envelopment analysis results for Gujarat districts.

\begin{tabular}{|c|c|c|c|c|c|c|}
\hline Districts & IMR & Scale efficiencies & Returns-to-scale & CCR score & Ranks* & Deviations from average \\
\hline Ahmadabad & 14 & 0.9178 & Increasing & 0.1777 & 20 & -0.2327 \\
\hline Amreli & 5 & 0.7568 & Increasing & 0.5236 & 6 & 0.1132 \\
\hline Anand & 6 & 0.5656 & Decreasing & 0.1885 & 19 & -0.2219 \\
\hline Banas Kantha & 2 & 1.0000 & Constant & 1.0000 & 1 & 0.5895 \\
\hline Bharuch & 5 & 0.6390 & Decreasing & 0.2556 & 14 & -0.1549 \\
\hline Bhavnagar & 3 & 0.9291 & Increasing & 0.8072 & 4 & 0.3968 \\
\hline Dohad & 2 & 0.8541 & Decreasing & 0.8541 & 3 & 0.4437 \\
\hline Gandhinagar & 6 & 0.5968 & Decreasing & 0.1989 & 17 & -0.2115 \\
\hline Jamnagar & 11 & 0.3354 & Increasing & 0.3354 & 11 & -0.0751 \\
\hline Junagadh & 5 & 0.7815 & Decreasing & 0.3126 & 12 & -0.0978 \\
\hline Kachchh & 7 & 0.6764 & Decreasing & 0.1933 & 18 & -0.2172 \\
\hline Kheda & 4 & 0.8214 & Decreasing & 0.4107 & 10 & 0.0003 \\
\hline Mahesana & 4 & 0.4171 & Decreasing & 0.2085 & 16 & -0.2019 \\
\hline Narmada & 4 & 0.6172 & Decreasing & 0.3086 & 13 & -0.1019 \\
\hline Navsari & 4 & 0.4337 & Decreasing & 0.2168 & 15 & -0.1936 \\
\hline Panch Mahals & 2 & 0.7950 & Decreasing & 0.7950 & 5 & 0.3846 \\
\hline Patan & 3 & 0.7332 & Decreasing & 0.4888 & 8 & 0.0784 \\
\hline Porbandar & 2 & 1.0000 & Constant & 1.0000 & 1 & 0.5895 \\
\hline Rajkot & 12 & 0.9852 & Increasing & 0.1740 & 21 & -0.2365 \\
\hline Surat & 14 & 0.9926 & Decreasing & 0.1418 & 24 & -0.2687 \\
\hline Surendranagar & 5 & 0.9144 & Increasing & 0.4435 & 9 & 0.0331 \\
\hline The Dangs & 7 & 0.5636 & Decreasing & 0.1610 & 22 & -0.2494 \\
\hline Vadodara & 10 & 0.4982 & Increasing & 0.4982 & 7 & 0.0878 \\
\hline Valsad & 10 & 0.7836 & Decreasing & 0.1567 & 23 & -0.2537 \\
\hline
\end{tabular}

IMR, infant mortality rate; CCR, Charnes, Cooper, and Rhodes. *The highest rank is denoted as 1 (top rank). 
Bhavnagarare, is thus among those which remain better and higher than the other 6 (excluding two districts having CCR as one) in the above average group. Further, if we look at the workload in these districts in terms of outdoor (OPD) and indoor patients (IPD), we find that it is very high in the districts of Vadodara and Rajkot followed by Ahmadabad. However, the low performing districts like Ahmadabad and Surat are also having very low availability of medical manpower per 10 thousand people. This is presented in Appendix Tables 1 and 2. It could be observed that all these three districts have very low ranking in terms of medical officers, lady medical officer, AYUSH doctors and pharamacists (columns 1 to 4 and rows 3 and 26). Likewise, these two districts are also very low in terms of physical inputs like tribal beds, non-tribal beds, total beds, sub-centers, primary health centers (PHCs) and CHCs (columns 6-12). By contrast, Valsad district is much better off in terms of all these inputs (Appendix Table 2, last row). This suggests that the efficiency in Valsad needs an improvement much more than the other districts, whereas districts like Ahmedabad and Surat need more of both medical manpower and facilities. Even in the case of Vadodara and Rajkot, the ranking in terms of most of medical manpower and facilities is low and these districts may also receive benefit by additional inputs.

We calculated further rank correlations of different variables with CCR deviations from group average. These are presented in Appendix Table 3.

The variables for which this correlation was calculated included total literacy rural, male literacy rural, female literacy rural, total literacy urban male literacy urban, female literacy, urban, total literacy, total male literacy, total female literacy, PHC OPD, CHC OPD, sub-district/district+civil hospital OPD, total OPD, PHC IPD, CHC IPD, sub-district/district+civil hospital IPD, total IPD, inhabitated villages, drinking water whole year, drinking water fair season, population in thousands, population density sq.km., sex ratio per '000 males, and urban population percent. Out of these, a statistically significant rank correlation at 5\% level with CCR deviations was observed for the total literacy rural, male literacy rural, female literacy rural, total literacy urban male literacy, urban femalel iteracy, urban total literacy, total male literacy, total female literacy and sex ratio per '000 males (Appendix Table 4). We used these variables to explain the deviations from mean of individual district CCR scores. The results presented in Appendix Table 4 indicate that increasing the male total literacy and female literacy urban has led to a decline in deviations across districts with a very small magnitude (coefficients are low; Appendix Table 4). The major variations as seen in CCR scores in Table 5 are due to the differences in an efficient utilization of major health inputs in some districts like Valsad, whereas for some districts like Ahmadabad and Surat lower availability of medical manpower and facilities seem to be the reason for their relative low efficiency. Fourteen districts, which have the CCR scores lower than the group average of .4105 , need to improve their input effectiveness to come up to an average level. Another 10 districts, which are above the group average, should aim towards bridging the gap between them and the top-ranking district.

Our results of Gujarat sub-state level analysis are also in line with similar studies in India. For instance, results are similar to a study conducted in another rich income state like Punjab, ${ }^{14}$ where poorer performance in some districts was also attributed to a scarcity of adequate medical and para-medical manpower. Likewise, inequitable distribution of beds and dispensaries, availability of skilled attention at birth and inadequate staffing relative to patient load in less urbanized districts of another high income, namely Maharashtra, are in line with our analysis of district level in Gujarat. However, unlike other district level Indian studies like the one conducted in Karnataka, here we have not considered factors external to the healthcare system in detail.

\section{Conclusions}

Our results pertaining to district level health system efficiency in Gujarat state indicate that some of the districts, like Valsad, have a low efficiency in utilization of inputs given their workload per health institutions. There are also other districts, like Rajkot, Vadodara, Ahmedabad and Surat, which need more of these inputs to enhance their output and efficiency. One policy factor, namely freeze in permanent recruitment of doctors in Gujarat, might also have aggravated the problem in the latter districts. ${ }^{17}$ Increased inputs, however, may not always guarantee the desirable outcomes. The utilization of these incremental inputs is also required to be optimal, as is presumed here. However, our analysis has the limitation to look into optimal utilization levels, as it is a matter of additional data and an estimation of that kind, which is not attempted here. Another limitation of our study is that we have used a cross section analysis. More validation of these benefits may be possible if it is extended using panel data models. Further applicability of our results can be confirmed only if there exists additional information on case mix, pattern of utilization and outcome of certain time-motion studies on different treatment procedures. There is a mix of both ineffi- ciency and inadequacy of the inputs, which is reflected in our results. Further exploration to observe individual input utilization efficiency - with additional budgetary resources - may help the Gujarat state health system to achieve the lowest IMR across the Indian states in a short period of time, thus leading to more efficient health outcomes.

\section{References}

1. WHO. The world health report, 2000, health systems: improving performance. Geneva: World Health Organization; 2000.

2. Murray CJL, Frenk J. A WHO framework for health system performance assessment. Global programme on evidence and information for policy. Washington, DC: World Bank; 1999.

3. Worthington AC. Frontier efficiency measurement in health care: a review of empirical techniques and selected applications. Med Care Res Rev 2004;61:135-70.

4. Hollingsworth B, Wildman J. The efficiency of health production: re-estimating the WHO panel data using parametric and nonparametric approaches to provide additional information. Clayton: Monash University; 2002.

5. Jamison DT, Sandbu M, Wang J. Cross country variation in mortality decline, 1962-87: the role of country specific technical progress. Geneva: World Health Organization; 2002.

6. Salomon JA, Mathers CD, Murray CJL, Ferguson B. Method for life expectancy and healthy life expectancy uncertainty analysis. Global programme on evidence for health policy. Geneva: World Health Organization; 2001.

7. Evans DB, Tandon A, Murray CJL, Lauer JA. The comparative efficiency of national health systems in producing health: an analysis of 191 countries. Geneva: World Health Organization; 2001.

8. Wang J, Jamison DT, Bos E, et al. Measuring country performance on health: selected indicators for 115 countries. Washington, DC: IBRD/World Bank; 1999.

9. Sankar D, Kathuria V. Health system performance in rural India. Efficiency estimates across states. Econ Polit Weekly 2004;39:1427-33.

10. Fried HO, Lovell CA, Schmidt SS. The measurement of productive efficiency: techniques and applications. New York, NY: Oxford University Press; 1993.

11. Charnes A, Cooper WW, Lewin AY, Seiford LM. Data envelopment analysis: theory, methodology and applications. Boston, 
MA: Kluwer; 1995.

12. Coelli T, Rao DSP, Battese G. An introduction to efficiency and productivity analysis. Boston, MA: Kluwer; 1998.

13. Hollingsworth B, Dawson PJ, Maniadakis $\mathrm{N}$. Efficiency measurement of health care: a review of non-parametric methods and applications. Health Care Manage Sci
1999;2:161-72.

14. Purohit BC. Efficiency of social sector expenditure in India. London: Routledge/Francis and Taylor; 2014.

15. Government of India. Annual health survey bulletin, 2012-13. New Delhi: Ministry of Home Affairs, Government of India; 2015.

16. Government of Gujarat. Health statistics,
Gujarat, 2010-11. Gandhinagar: Government of Gujarat; 2012.

17. Government of India. Managing human resources for health in India: a case study of Gujarat and Madhya Pradesh. New Delhi: Central Bureau of Health Intelligence; 2007. 